\title{
A WSi-WSiN-Pt Metallization Scheme for Silicon Carbide-Based High Temperature Microsystems
}

\author{
Ha-Duong Ngo ${ }^{1,2, *}$, Biswajit Mukhopadhyay ${ }^{1}$, Piotr Mackowiak ${ }^{1}$, Kevin Kröhnert ${ }^{1}$, \\ Oswin Ehrmann ${ }^{1,3}$ and Klaus-Dieter Lang 1,3 \\ 1 Center of Microperipheric Technologies, Fraunhofer Institute IZM, Berlin 13355, Germany; \\ Biswajit.Mukhopadhyay@izm.fraunhofer.de (B.M.); Piotr.Macokowiak@izm.fraunhofer.de (P.M.); \\ Kevin.Kroehnert@izm.fraunhofer.de (K.K.); Oswin.Ehrmann@izm.fraunhofer.de (O.E.); \\ kdlang@izm.fraunhofer.de (K.-D.L.) \\ 2 University of Applied Sciences, FB I, Microsystems Engineering, Berlin 12459, Germany \\ 3 Microsensor and Actuator Technology, Technical University Berlin, Berlin 10623, Germany \\ * Correspondence: ha-duong.ngo@izm.fraunhofer.de; Tel.: +49-30-314-72-772; Fax: +49-30-314-72-660 \\ Academic Editor: Nam-Trung Nguyen \\ Received: 29 July 2016; Accepted: 6 October 2016; Published: 20 October 2016
}

\begin{abstract}
In this paper, we present and discuss our new WSi-WSiN-Pt metallization scheme for SiC-based microsystems for applications in harsh environments. Stoichiometric material WSi was selected as contact material for SiC. The diffusion barrier material WSiN was deposited from the same target as the contact material in order to limit the number of different chemical elements in the scheme. Our scheme was kept as simple as possible regarding the number of layers and chemical elements. Our scheme shows very good long-term stability and suitability for SiC-based microsystems. The experimental evaluation concept used here includes a combination of physical, electrical, and mechanical analysis techniques. This combined advance is necessary since modern physical analysis techniques still offer only limited sensitivity for detecting minimal changes in the metallization scheme.
\end{abstract}

Keywords: microelectromechanical system (MEMS); SiC-based microsystems; sensors for harsh environment; sensors for high temperature

\section{Introduction}

In recent years, there has been an increasing demand for high temperature electronics, operating in harsh environments and at temperatures up to $500{ }^{\circ} \mathrm{C}$. Various key industrial sectors such as petroleum \& gas, geothermal logging, nuclear power, and the automotive and aerospace industries require materials that maintain reliability under such hostile conditions. Table 1 shows an overview of applications and temperature ranges.

Table 1. High temperature applications and associated temperature ranges.

\begin{tabular}{ccc}
\hline Application & Measuring Site & Temperature $\left({ }^{\circ} \mathrm{C}\right)$ \\
\hline \multirow{2}{*}{ Power Plant } & Power Engine, & $500-600{ }^{\circ} \mathrm{C}$ \\
& Turbine, & $800{ }^{\circ} \mathrm{C}$ \\
& Waste Gas Cleaning & $300-400{ }^{\circ} \mathrm{C}$ \\
\hline Logging & Drilling Head & $250-300{ }^{\circ} \mathrm{C}$ \\
\hline Plastic Injection & Plasticization Area or at Nozzle & $150-500{ }^{\circ} \mathrm{C}$ \\
\hline Petroleum & Reactor & $200-1000{ }^{\circ} \mathrm{C}$ \\
\hline Medicine & Instruments Sterilization & $150-300{ }^{\circ} \mathrm{C}$ \\
\hline Automotive & Combustion Engine & $150-2000{ }^{\circ} \mathrm{C}$ \\
\hline
\end{tabular}


One of the crucial features for successful device performance is the availability of a suitable long-term stable high temperature metallization scheme, typically including a diffusion barrier layer, which prevents a metallurgical reaction between metallization and semiconductor substrate, a contact layer and an interconnect layer. Ternary amorphous metallic thin films such as Ti-Si-N [1-4], Mo-Si-N [5,6], Zr-Si-N [7-10], Ta-Si-N [11-16], and W-Si-N [17-23] have received considerable attention for high temperature diffusion barrier applications. These materials have shown to be chemically inert against reactions with gold [4,11,24], silver [11], copper [12-14,16,17,20], aluminum [18,25], and platinum [26-28] metallization at elevated temperatures, thereby providing the low diffusivities required for a diffusion barrier. Moreover, their amorphous structure sustains even at temperatures above $800{ }^{\circ} \mathrm{C}[15,20,21]$, preventing the formation of grain boundaries which act as rapid diffusion paths.

However, most annealing experiments published to date have been limited to rather short annealing times of typically $30-90 \mathrm{~min}$. This is sufficient for applications such as copper ultra large scale integration (ULSI) interconnects [5,13,17,22], dynamic random-access memory (DRAM) applications $[29,30]$, and other devices that require short-term high temperature processing, but tells us little about the actual long-term high temperature stability of the metallization schemes presented.

Silicon carbide is considered to be the most promising semiconductor for the above-mentioned high-temperature and harsh-environment applications, as it features a unique combination of physical, electrical, mechanical, and chemical properties. This material is extremely hard and robust with high thermal stability. It has a wide bandgap, which allows operation at high temperatures and in high radiation environments.

In this work, we have investigated layered contact structures consisting of a $200 \mathrm{~nm} \mathrm{WSi} 2$ contact layer, a $200 \mathrm{~nm}$ W-Si-N diffusion barrier, and $150 \mathrm{~nm} \mathrm{Pt}$ top metallization for silicon carbide-based sensors. A systematic search for suitable materials for each of the three functional layers is extremely difficult. First of all, materials must be characterized and investigated down to a near-atomic level in order to understand the solid-state reactions and electronic properties of clusters involved in the contact formation and interdiffusion [31].

Stoichiometric layer of tungsten silicide $\left(\mathrm{WSi}_{2}\right)$ was chosen as contact layer of a $6 \mathrm{H}-\mathrm{SiC}$ substrate. This material is known for its low electrical resistivity and excellent thermal and chemical stability. Deposition and patterning techniques for the silicide layer are well developed, and low-resistivity ohmic contact to $\mathrm{SiC}$ have been demonstrated. Works with other transition metal silicides such as $\mathrm{TaSi}_{2}$ are ongoing and will be published later.

The barrier layer is WSiN. It is focused on the thermal stability of amorphous W-Si-N thin films and their performance as diffusion barriers between $\mathrm{WSi}_{2}$ and platinum. Samples were annealed at $500{ }^{\circ} \mathrm{C}$ for up to $1000 \mathrm{~h}$ in $\mathrm{N}_{2}$ ambient conditions and examined via X-ray diffraction (XRD) and Auger electron spectroscopy (AES) analysis.

Platinum is known for its excellent high temperature stability and could be used as top metallization for the chip and bond interconnect material for micro welding. In order to get the best adhesion of $\mathrm{Pt}$, sputtering at room temperature was chosen for the platinum deposition process.

\section{Experimental Details}

\subsection{Chip Layout and Materials}

The test chip layout is shown in Figure 1. There are two bone structures and two square van-der-Pauw structures. The upper van-der-Pauw structures are designed so that the metallization is in contact with the substrate. Those can be used to characterize the metallization in contact with the $\mathrm{SiC}$ substrate. In the lower structures, the metallization is insulated from semiconductor substrate, so that structures can be used to measure the metallization's sheet resistance without influence of the subjacent substrate. The upper Greek cross structure can be used to determine the semiconductor sheet resistance, while the lower one can be used to determine the sheet resistance of the metallization 
stack. The layout consists of four implanted resistors and mimics a Wheatstone-bridge measurement circuit, as is normally used in sensor devices. Three linear transmission-line matrix (TLM) test structures, two circular TLM structures, and two cross-bridge Kelvin resistor structures have been used for measuring the specific contact resistivity. In addition, the I-V characteristics of the metal semiconductor contact can be measured using the contact pads of the linear TLM structure. The I-V curve indicates whether an ohmic contact has been formed, and changes in the curve's slope indicate changes in the metallization's sheet resistance or contact resistivity.

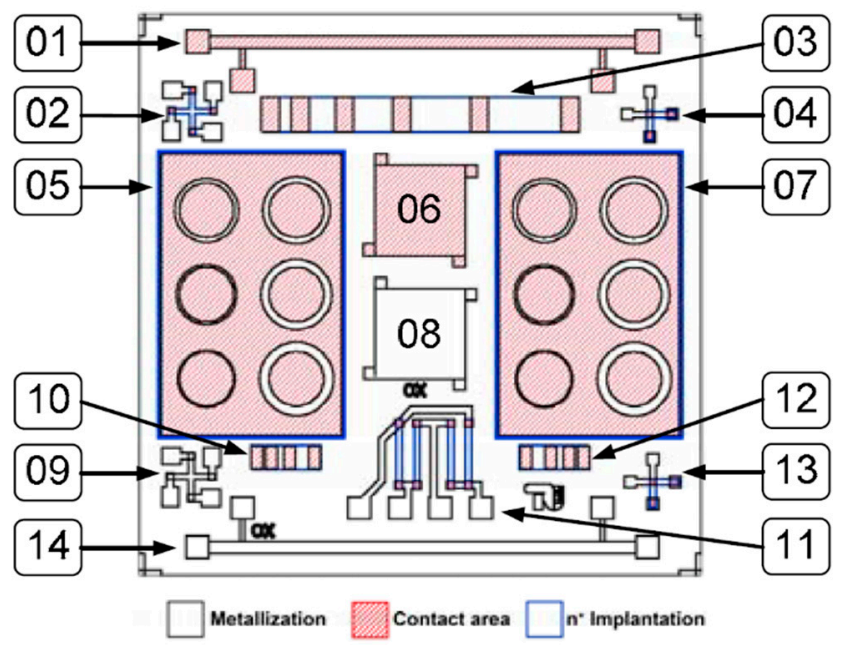

Figure 1. Test chip layout for electrical tests of the contact resistivity in the SiC-WSi-WSiN-Pt metallization system. The upper bone structure (structure 1) and the van-der-Pauw structures (structure 6) are used to characterize the metallization in contact with the substrate. Bone structures (structures 8 and 14) are used to measure the metallization sheet resistance. The Greek cross structure (structure 2) can be used to determine the semiconductor sheet resistance. The Greek cross structure (structure 9) can be used to determine the sheet resistance of the metallization stack. The structure 11 consists of 4 resistors is commonly used in a sensor device. The linear TLM structures $(3,10$ and 12) and circular TLM (5 and 10) and two cross-bridge Kelvin resistors (4 and 13) are used to measure the specific contact resistivity.

Silicon wafers were used in this work (to test thermal stability) were purchased from Okmetic Ltd., Vantaa, Finland. The $100 \mathrm{~mm}$ material was (100) oriented, with an $n$-type with a typical resistivity of $1-10 \Omega \cdot \mathrm{cm}$ and a thickness of $525 \mu \mathrm{m}$. The substrates were oxidized to obtain $100 \mathrm{~nm} \mathrm{SiO}_{2}$ as insulation before deposition of metallization.

The $6 \mathrm{H}-\mathrm{SiC}$ wafers used had a thickness of $250 \mu \mathrm{m}$ and were oriented $8^{\circ}$ off-axis. The silicon face was prepared using Epi-ready polishing technique. The substrates were nitrogen-doped with a typical resistivity of $70 \mathrm{~m} \Omega \cdot \mathrm{cm}$. Two epitaxial layers were deposited on the polished face of the wafers. First, $12 \mu \mathrm{m} \pm 2 \mu \mathrm{m}$ of $p$-SiC, doped with an aluminum concentration of $3 \times 10^{17} \mathrm{~cm}^{-3}$, were deposited, followed by $1.3 \mu \mathrm{m} \pm 0.2 \mu \mathrm{m}$ of $n$-SiC doped with a nitrogen concentration of $5 \times 10^{18} \mathrm{~cm}^{-3}$. The epitaxial layers improve the surface quality of the substrates by closing micropipe defects and create an abrupt $p n$ junction for the later realization of piezoresistors by mesa etching.

\subsection{Investigation of Ohmic Contact between WSi and SiC}

Tungsten silicide contact layer was deposited from a Cerac $200 \mathrm{~mm}$ high-density, hot-pressed $\mathrm{WSi}_{2.3}$ composite target with a purity of 2N5 (99.5\%). The layer thickness was adjusted to $150 \mathrm{~nm}$. The resistivity was measured to be $480 \mu \Omega \cdot \mathrm{cm}$.

A contact formation step was performed in order to achieve a low resistivity ohmic contact and transform the amourphous silicide layer into their respective high-temperature phase. The wafers 
were annealed in a Xerion Xreact 1000 rapid thermal processing system (Xerion Advanced Heating $\mathrm{GmbH}$, Freiberg, Germany) for $1 \mathrm{~min}$ at $1100{ }^{\circ} \mathrm{C}$ in a high purity argon atmosphere. The resistivity of the annealed layer was measured to be $50 \mu \Omega \cdot \mathrm{cm}$.

The I-V curves of the samples, annealed at different temperatures, are depicted in Figure 2 below.

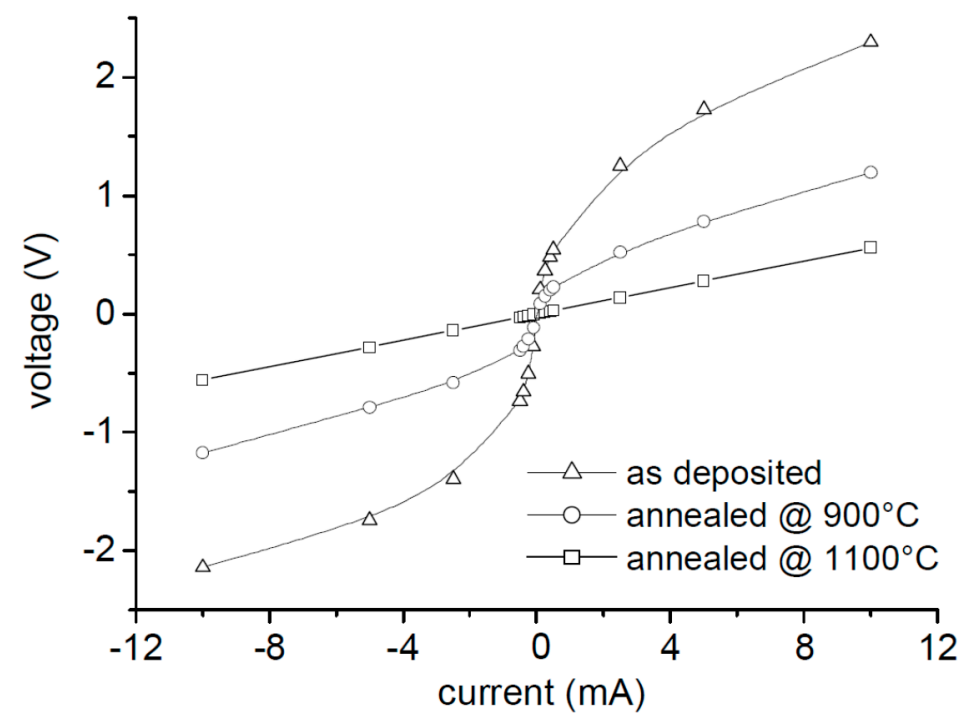

Figure 2. I-V characteristics of samples from SiC-wafer after rapid thermal annealing (RTA) at different temperatures.

As deposited, the WSi-SiC system shows a strong non-linear behavior. With increasing annealing temperature, the I-V characteristic becomes increasingly linear. For an annealing time of 1 min at $1100{ }^{\circ} \mathrm{C}$, we reached a perfectly ohmic behavior over a broad current range, as illustrated in Figure 3.

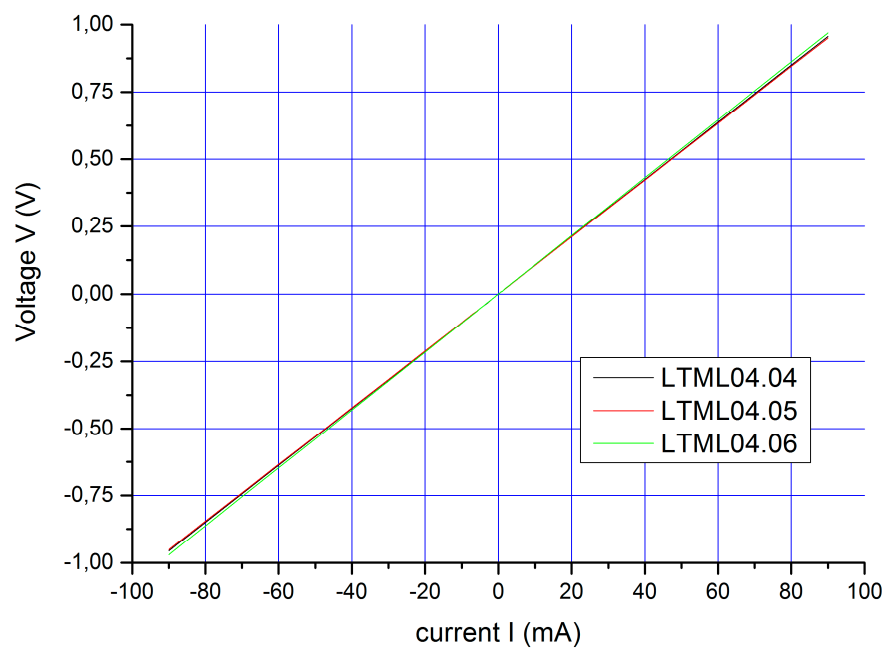

Figure 3. I-V curve measured at a linear transmission line model (LTLM)-structure on a SiC-wafer (200 nm WSi ${ }_{1.8}$ on $\left.6 \mathrm{H}-\mathrm{SiC}\right)$, annealed for $1 \mathrm{~min}$ at $1100{ }^{\circ} \mathrm{C}$.

All tested chips show a perfectly linear $\mathrm{I}-\mathrm{V}$ behavior in a wide range of $\pm 100 \mathrm{~mA}$. This confirms our results and demonstrates that the WSi contact layer forms ohmic contacts on $6 \mathrm{H}-\mathrm{SiC}$.

The contact resistivity was measured using the Kelvin test structure. The minimum contact resistivity was measured to be $6.2 \times 10^{-4} \Omega \cdot \mathrm{cm}^{2}$, and the mean value is $6.6 \times 10^{-4} \Omega \cdot \mathrm{cm}^{2}$. This value again confirms previous results. 


\subsection{Investigation of Thermal Stability of the WSiN Barrier Layer}

For our experiments, unpatterned 4 inch (100)-Si wafers ( $n$-type, phosphorous, $1-10 \Omega \cdot \mathrm{cm}$ ) were used as substrate material. The substrates were oxidized by dry thermal oxidation at $1000{ }^{\circ} \mathrm{C}$ in $\mathrm{O}_{2}$ ambience to create $100 \mathrm{~nm}$ of $\mathrm{SiO}_{2}$. WSi 2 contact layers with a thickness of $200 \mathrm{~nm}$ were sputter-deposited in a Leybold Heraeus Z660 Load Lock Sputtering System (Leybold GmbH, Cologne, Germany) from a high purity $\mathrm{WSi}_{2.3}$ composite target. The thin films were DC magnetron-sputtered at $1.5 \mathrm{~kW}$ forward power using krypton gas at a pressure of $5 \times 10^{-3} \mathrm{mbar}$. A rapid thermal processing system Xerion Xreact 1000 was then used to anneal the samples for $1 \mathrm{~min}$ at $1000{ }^{\circ} \mathrm{C}$ in a high purity argon flow. W-Si-N barrier layers with a thickness of $200 \mathrm{~nm}$ were deposited by reactive sputtering using the same $\mathrm{WSi}_{2.3}$ target as that of the contact layers. Barrier layers with three different compositions were direct current (DC) magnetron-sputtered at $1.0 \mathrm{~kW}$ forward power using gas mixtures of $10 \mathrm{sccm} \mathrm{N} \mathrm{N}_{2}+80 \mathrm{sccm} \mathrm{Ar}, 5 \mathrm{sccm} \mathrm{N} \mathrm{N}_{2}+85 \mathrm{sccm} \mathrm{Ar}$, and $2 \mathrm{sccm} \mathrm{N} \mathrm{N}_{2}+88 \mathrm{sccm}$ Ar, respectively. Finally, $150 \mathrm{~nm}$ of platinum were sputter-deposited at room temperature.

For all further experiments, the wafers were cut into pieces of about $20 \mathrm{~mm} \times 30 \mathrm{~mm}$. The samples were annealed for up to $1000 \mathrm{~h}$ in a Centrotherm vertical tube furnace at $500{ }^{\circ} \mathrm{C}$ in a $8 \mathrm{slm}$ high purity $\mathrm{N}_{2}$ flow. After $24 \mathrm{~h}, 100 \mathrm{~h}, 500 \mathrm{~h}$, and $1000 \mathrm{~h}$, dedicated samples were removed from the furnace and examined via optical microscopy and scanning electron microscopy (SEM) to study the surface morphology of the metallization scheme. XRD analysis was used in order to characterize the microstructure and thermal stability of the W-Si-N barrier films. XRD measurements were performed at room temperature using $\operatorname{CoK} \alpha$ radiation, a step width of $0.05^{\circ}$, and scattering angles of $2 \theta=20-80^{\circ}$. Auger electron spectroscopy (AES) was employed to determine the film composition and study the extent of thin film interdiffusion between the three metallization layers.

\subsubsection{Elemental Composition of $\mathrm{W}-\mathrm{Si}-\mathrm{N}$}

Three sets of W-Si-N samples with different nitrogen amounts were sputtered-deposited using various nitrogen partial flow rates. Table 2 shows the deposition conditions and atomic composition of the investigated $\mathrm{W}-\mathrm{Si}-\mathrm{N}$ barrier layers as determined via AES analysis. The samples are labelled with letters A-C for abbreviation. The as-deposited layers have an atomic composition of $\mathrm{W}_{27} \mathrm{Si}_{70} \mathrm{~N}_{3}$, $\mathrm{W}_{25} \mathrm{Si}_{69} \mathrm{~N}_{5}$, and $\mathrm{W}_{25} \mathrm{Si}_{66} \mathrm{~N}_{9}$, respectively. By increasing the nitrogen partial flow from 2 to $10 \mathrm{sccm}$, the nitrogen content in the deposited W-Si-N layers increased from 2.5 to 9 atom \%. At the same time, the $\mathrm{Si}-\mathrm{W}$ atomic ratio decreased from 2.7 to 2.38 . All samples furthermore contain 1.4 atom \% of argon and traces of oxygen (below 0.5 atom \%) and carbon (below 0.2 atom \%), which is in the rage of the respective detection limit.

Table 2. Atomic composition of ternary metal silicon nitride barrier layers tested in this study as determined by AES analysis.

\begin{tabular}{cccccc}
\hline Target & Me-Si Ratio & $\begin{array}{c}\mathbf{N}_{\mathbf{2}} \text { Partial } \\
\text { Pressure }(\mathbf{\%})\end{array}$ & $\begin{array}{c}\text { Resistivity } \\
(\mu \boldsymbol{\Omega} \cdot \mathbf{c m})\end{array}$ & $\begin{array}{c}\text { Atomic } \\
\text { Composition }\end{array}$ & $\begin{array}{c}\text { Me-Si Ratio } \\
\text { in Film }\end{array}$ \\
\hline $\mathrm{WSi}_{2.3}$ & $1: 2.3$ & 2.2 & 479.4 & $\mathrm{~W}_{27} \mathrm{Si}_{70} \mathrm{~N}_{3}$ & $1: 2.6$ \\
$\mathrm{WSi}_{2.3}$ & $1: 2.3$ & 5.6 & 529.6 & $\mathrm{~W}_{25} \mathrm{Si}_{70} \mathrm{~N}_{5}$ & $1: 2.8$ \\
$\mathrm{WSi}_{2.3}$ & $1: 2.3$ & 11.1 & 595 & $\mathrm{~W}_{25} \mathrm{Si}_{66} \mathrm{~N}_{9}$ & $1: 2.6$ \\
\hline
\end{tabular}

\subsubsection{Microstructure of WSiN}

The thermal stability of the WSiN thin films was investigated. Samples with WSiN layers on oxidized Si substrates were processed and analyzed via XRD. Figure 4 shows the XRD spectrums for films deposited on $\mathrm{SiO}_{2}$, annealed at $500{ }^{\circ} \mathrm{C}$ in nitrogen ambient conditions for $100 \mathrm{~h}$. The upper curve shows the spectrum of the WSiN layer and the lower curve the Si substrate, measured on the backside of the sample. 


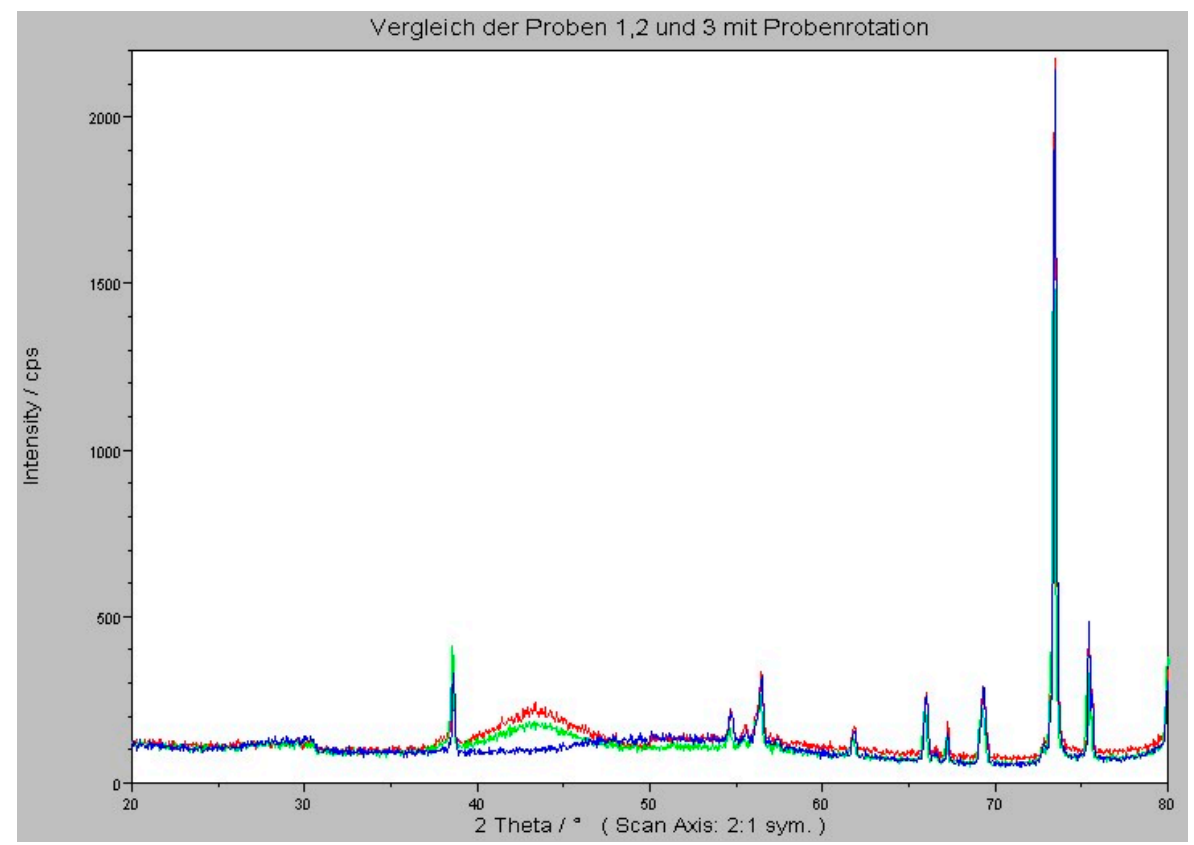

Figure 4. XRD analysis of samples after $100 \mathrm{~h}$ annealing at $500^{\circ} \mathrm{C}$ in $\mathrm{N}_{2}$.

All films present amorphous structures in the as-deposited and annealed conditions when analyzed by XRD diffraction. Only a broad peak centered at $2 \theta=43^{\circ}$ was detected in the XRD patterns.

The broad peak at $2 \theta=43^{\circ}$ is indicative of an amorphous layer. No crystalline compounds were found in the deposited layers. All peaks originate from the Si substrate. This composition is thermally stable at temperatures up to $500{ }^{\circ} \mathrm{C}$. This is in agreement with the literature [19]. Thermal stability, in the amorphous phase, of the WSiN films is crucial for the use of this material as a diffusion barrier. Our results show that all three WSiN films are thermally stable for a long time. Crystallization leads to the formation of grain boundaries, which act as rapid diffusion paths and lead to barrier failure.

Samples with platinum deposited by evaporation at $350^{\circ} \mathrm{C}$ shows small blisters after annealing for $100 \mathrm{~h}$ at $500{ }^{\circ} \mathrm{C}$ in air as depicted in Figure 5 .

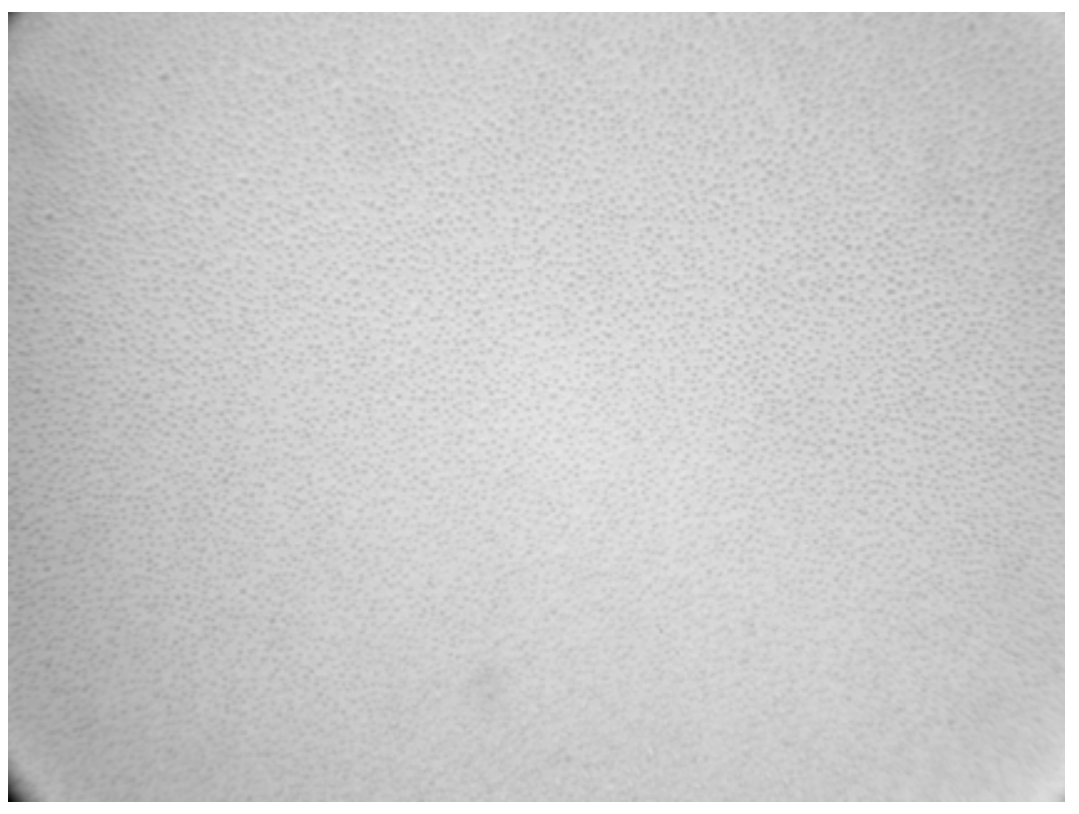

Figure 5. WSi-WSiN-Pt metallization after $100 \mathrm{~h}$ of annealing at $500{ }^{\circ} \mathrm{C}$ in air (magnification $500 \times$ ). 


\subsection{Characterization of the New Metallization Scheme}

In order to test the barrier capabilities of our new metallization scheme, a sample was annealed for $1050 \mathrm{~h}$ at $500{ }^{\circ} \mathrm{C}$ in $\mathrm{N}_{2}$ ambient conditions for AES analysis. The result is very promising. As depicted in Figure 6, there is no platinum diffusion into the WSiN barrier layer.

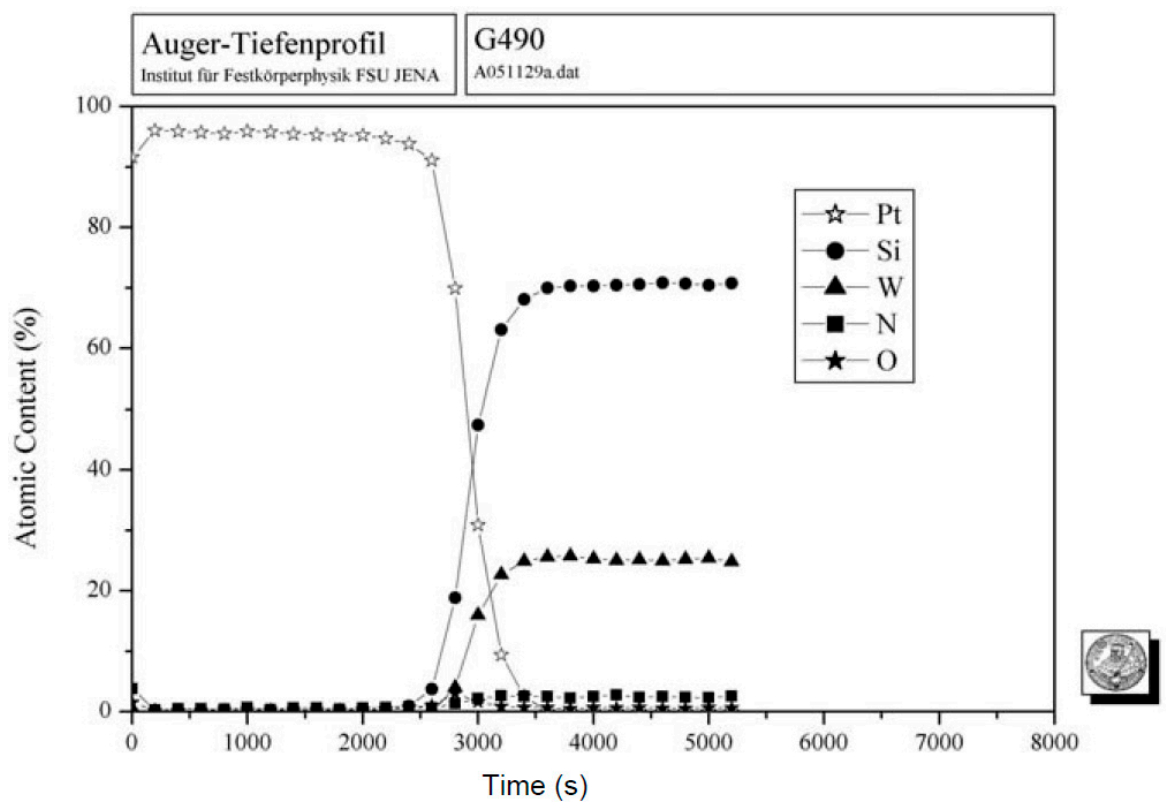

Figure 6. Auger electron spectroscopy (AES) analysis of a sample with a WSiN barrier layer and $150 \mathrm{~nm}$ Pt top metallization, annealed for $1050 \mathrm{~h}$ at $500{ }^{\circ} \mathrm{C}$ in $\mathrm{N}_{2}$ ambient conditions.

Silicon carbide test chips were processed using the complete, optimized WSi-WSiN-Pt metallization system. Chips were annealed at $500{ }^{\circ} \mathrm{C}$ in $\mathrm{N}_{2}$ ambient conditions for $70 \mathrm{~h}, 120 \mathrm{~h}$, and $410 \mathrm{~h}$, respectively, in order to investigate the change in contact resistivity upon annealing. After an initial increase of $1.42 \%$, the contact resistivity remains almost constant. The maximum variation after the initial anneal is as low as $0.14 \%$.

\section{Conclusions}

In this work, new high-temperature-stable metallization concept for SiC-based microsystems was developed. The metallization concept comprises the choice of materials as well as the setup. After processing, a multilayer, multi-element metallization system is generally not in state of thermodynamic equilibrium. Subsequent long-term high-temperature annealing provides the activation energy for material redistribution and chemical reactions towards an energetically favorable state. These mechanisms cause the electrical contact to become unstable. The advance in this study was to minimize the driving force for such reactions within the metallization stack. Stoichiometric material WSi was selected as contact material for SiC. The diffusion barrier material WSiN was deposited from the same target as the contact material in order to limit the number of different chemical elements in the scheme.

$\mathrm{WSi}_{2}$ contact layers with a thickness of $150 \mathrm{~nm}$ were sputter deposited in a Leybold Heraeus Z660 Load Lock Sputtering System from a high purity $\mathrm{WSi}_{2.3}$ composite target. A rapid thermal processing system Xerion Xreact 1000 was then used to anneal the samples for $1 \mathrm{~min}$ at $1000{ }^{\circ} \mathrm{C}$ in a high-purity argon flow. This is necessary to transform the amorphous WSi layers into their stable tetragonal phase, yielding low layer resistivity, ohmic linear electrical behaviour, low intrinsic stress, and high temperature stability. 
The thermal stability of WSiN thin films was investigated. All films present amorphous structures in the as deposited and annealed condition, when analyzed via XRD. Only a broad peak centered at $2 \theta=43^{\circ}$ is detected in the XRD patterns. The broad peak at $2 \theta=43^{\circ}$ is indicative of an amorphous layer. No crystalline compounds were found in the deposited layers. All peaks come from the $\mathrm{Si}$ substrate. This composition is thermally stable at temperatures up to $500{ }^{\circ} \mathrm{C}$.

Our scheme was kept as simple as possible regarding the number of layers and chemical elements. Our scheme shows very good long-term stability and suitability for SiC-based microsystems.

The experimental evaluation concept used here includes a combination of physical, electrical, and mechanical analysis techniques. This combined advance is necessary since modern physical analysis techniques still only offer limited sensitivity for detecting minimal changes in the metallization scheme.

Author Contributions: The concept and idea were developed by Ha-Duong Ngo. The processing of the samples was performed by Biswajit Mukhopadhyay, Piotr Mackowiak, and Kevin Kröhnert Experiments and analyses were performed by Ha-Duong Ngo, Biswajit Mukhopadhyay, Piotr Mackowiak, Kevin Kröhnert, Oswin Ehrmann, Klaus-Dieter Lang, and Ha-Duong Ngo wrote the paper.

Conflicts of Interest: The authors declare no conflict of interest.

\section{References}

1. Ee, Y.C.; Chen, Z.; Law, S.B.; Xu, S.; Yakovlev, N.L.; Lai, M.Y. Copper diffusion in Ti-Si-N layers formed by inductively coupled plasma implantation. Appl. Surf. Sci. 2006, 253, 530-534. [CrossRef]

2. Park, J.-S.; Kang, S.-W.; Kim, H. Growth mechanism and diffusion barrier property of plasma-enhanced atomic layer deposition Ti-Si-N thin films. J. Vac. Sci. Technol. B 2006, 24, 1327-1332. [CrossRef]

3. No, J.T.; O, J.H.; Lee, C. Evaluation of Ti-Si-N as a diffusion barrier between copper and silicon. Mater. Chem. Phys. 2000, 63, 44. [CrossRef]

4. Shalish, I.; Shapira, Y. Thermal stability of a Ti-Si-N diffusion barrier in contact with a Ti adhesion layer for Au metallization. J. Vac. Sci. Technol. B 1999, 17, 166. [CrossRef]

5. Reid, J.S.; Kowala, E.; Ruiz, R.P.; Nicolet, M.A. Evaluation of amorphous (Mo, Ta, W)-Si-N diffusion barriers for Si-Cu metallizations. Thin Solid Films 1993, 236, 319. [CrossRef]

6. Sun, S.C.; Yap, H.K.; Chen, C.A.; Lin, P. Evaluation of amorphous (Ta, W, Mo)-Si-N diffusion barriers between $\mathrm{Cu}$ and $\mathrm{Si}$. In Proceedings of the 6th international Conference on Solid-State and Integrated Circuit Technology, Shanghai, China, 22-25 October 2001; Volume 1, pp. 397-399.

7. Zeman, P.; Musil, J. Difference in high-temperature oxidation resistance of amorphous $\mathrm{Zr}-\mathrm{Si}-\mathrm{N}$ and W-Si-N films with a high Si content. Appl. Surf. Sci. 2006, 252, 8319. [CrossRef]

8. Song, Z.X.; Xu, K.W.; Cheng, H. The characterization of $\mathrm{Zr}-\mathrm{Si}-\mathrm{N}$ diffusion barrier films with different sputtering bias voltage. Thin Solid Films 2004, 468, 203-207. [CrossRef]

9. Wang, Y.; Zhu, C.C.; Song, Z.X.; Liu, J.H. Diffusion barrier study on TaSi and TaSiN. Chin. J. Semicond. 2004, 25,1634 .

10. Wang, Y.; Zhu, C.C.; Song, Z.X.; Ying, L. High temperature stability of $\mathrm{Zr}-\mathrm{Si}-\mathrm{N}$ diffusion barrier in $\mathrm{Cu} / \mathrm{Si}$ contact system. Microeletron. Eng. 2004, 71, 69. [CrossRef]

11. Kuchuk, A.V.; Ciosek, J.; Piotrowska, A.; Kaminska, E.; Wawro, A.; Lytvyn, O.S.; Nowicki, L.; Ratajczak, R. Barrier properties of Ta-Si-N films in Ag-and Au-containing metallization. Vacuum 2004, 74, 195. [CrossRef]

12. Lee, Y.J.; Suh, B.-S.; Kwon, M.S.; Pak, C.-O. Barrier properties and failure mechanism of Ta-Si-N thin films for $\mathrm{Cu}$ interconnection. J. Appl. Phys. 1999, 85, 1927. [CrossRef]

13. Hübner, R.; Hecker, M.; Mattern, N.; Voss, A.; Acker, J.; Hoffmann, V.; Wetzig, K.; Engelmann, H.-J.; Zschech, E.; Heuer, H.; et al. Influence of nitrogen content on the crystallization behavior of thin Ta-Si-N diffusion barriers. Thin Solid Films 2004, 468, 183. [CrossRef]

14. Hübner, R.; Hecker, M.; Mattern, N.; Hoffmann, V.; Wetzig, K.; Heuer, H.; Wenzel, C.; Engelmann, H.-J.; Gehre, D.; Zschech, E. Effect of nitrogen content on the degradation mechanisms of thin Ta-Si-N diffusion barriers for $\mathrm{Cu}$ metallization. Thin Solid Films 2006, 500, 259. [CrossRef]

15. Olowolafe, J.O.; Rau, I.; Unruh, K.M.; Swann, C.P.; Jawad, Z.S.; Alford, T. Effect of composition on thermal stability and electrical resistivity of Ta-Si-N films. Thin Solid Films 2000, 365, 19. [CrossRef] 
16. Lai, L.W.; Chen, J.S.; Hsu, W.-S. Influence of TaSi atomic ratio on the interdiffusion between Ta-Si-N and Cu at elevated temperature. J. Appl. Phys. 2003, 94, 5396. [CrossRef]

17. Qu, X.-P.; Lu, H.; Peng, T.; Ru, G.-P.; Li, B.-Z. Effects of preannealing on the diffusion barrier properties for ultrathin W-Si-N thin film. Thin Solid Films 2004, 67, 462-463. [CrossRef]

18. Reid, J.S.; Kowala, E.; Garland, C.M.; Nicolet, M.-A. Amorphous (Mo, Ta, or W)-Si-N diffusion barriers for Al metallizations. J. Appl. Phys. 1996, 79, 1109. [CrossRef]

19. Vomiero, A.; Marchi, E.B.; Frabboni, S.; Quaranta, A.; Della Mea, G.; Mariotto, G.; Felisari, L.; Butturi, M. Effects of thermal annealing on the structural properties of sputtered W-Si-N diffusion barriers. Mater. Sci. Semicond. Process. 2004, 7, 325. [CrossRef]

20. Shimooka, Y.; Iijima, T.; Nakamura, S.; Suguro, K. Correlation of W-Si-N film microstructure with barrier performance against Cu diffusion. Jpn. J. Appl. Phys. 1997, 36, 1589. [CrossRef]

21. Marques, A.P.; Cavaleiro, A. Structural and mechanical properties of amorphous W-Si-N sputtered films after thermal annealing. Thin Solid Films 2003, 441, 150. [CrossRef]

22. Somatri-Boumrane, R.; Chevarier, N.; Chevarier, A.; Dutron, A.M.; Blanquet, E.; Madar, R. Ion beam analysis of ternary silicides $\mathrm{Me}-\mathrm{Si}-\mathrm{N}(\mathrm{Me}=\mathrm{Re}, \mathrm{Ta}, \mathrm{Ti}, \mathrm{W})$ thin films used as diffusion barriers in advanced metallization. Electron. Soc. Proc. 1997, 741, 25-97.

23. Vomiero, A.; Marchi, E.B.; Mariotto, G.; Quaranta, A.; della Mea, G.; Ottaviani, G.; Tonini, R.; Butturi, M.; Martinelli, G. Composition and resistivity changes of reactively sputtered $\mathrm{W}-\mathrm{Si}-\mathrm{N}$ thin films under vacuum annealing. Appl. Phys. Lett. 2006, 88, 031917. [CrossRef]

24. Shalish, I.; Shapira, Y. Stability of Schottky contacts with Ta-Si-N amorphous diffusion barriers and Au overlayers on 6H-SiC. J. Vac. Sci. Technol. B 2002, 18, 2477. [CrossRef]

25. Kowala, E.; Molarius, J.M.; Nieh, C.W.; Nicolet, M.-A. Amorphous Ta-Si-N thin-film alloys as diffusion barrier in $\mathrm{Al} / \mathrm{Si}$ metallizations. J. Vac. Sci. Technol. 1990, A8, 3006. [CrossRef]

26. Mrosk, J.W.; Berger, L.; Ettl, C.; Fecht, H.-J.; Fischerauer, G.; Dommann, A. Materials issues of SAW sensors for high-temperature applications. IEEE Trans. Ind. Electron. 2001, 48, 258. [CrossRef]

27. Lee, E.-M.; Shin, W.-C.; Choi, Y.-S.; Yoon, S.-G. Diffusion barrier characteristics of TaSiN for Pt/TaSiN/poly-Si electrode structure of semiconductor memory device. J. Electrochem. Soc. 2001, 148, G611. [CrossRef]

28. Letendu, F.; Hugon, M.C.; Voldoire, O.; Agius, B.; Berthier, C.; Lameille, J.M. Materials Research Society Symposium Proceedings; Cambridge University Press: Cambridge, UK, 2003.

29. Grill, A.; Jahnes, C.; Cabral, C., Jr. Layered TaSiN as an oxidation resistant electrically conductive barrier. J. Mater. Res. 1999, 14, 1604. [CrossRef]

30. Cabral, C., Jr.; Saenger, K.L.; Kotecki, D.E.; Harper, J.M.E. Optimization of Ta-Si-N thin films for use as oxidation-resistant diffusion barriers. J. Mater. Res. 2000, 15, 194. [CrossRef]

31. Gueorguiev, G.K.; Pacheco, J.M. Silicon and metal nanotemplates: Size and species dependence of structural and electronic properties. J. Chem. Phys. 2003, 119, 10313. [CrossRef]

(C) 2016 by the authors; licensee MDPI, Basel, Switzerland. This article is an open access article distributed under the terms and conditions of the Creative Commons Attribution (CC-BY) license (http://creativecommons.org/licenses/by/4.0/). 